\title{
Contactless Raman Spectroscopy-Based Monitoring of Physical States of Silyl-Modified Polymers during Cross-Linking
}

\author{
Boris Colin1, Olivier Lavastre ${ }^{*}$, Stéphane Fouquay1, Guillaume Michaud1, Frédéric Simon1, \\ Olivier Laferte1, Jean-Michel Brusson ${ }^{3}$
}

\author{
${ }^{1}$ Laboratory of Functional Materials, Institut Electronique Télecommunication Rennes, Unité Mixte Recherche 6164 Centre National \\ Recherche Scientifique, University of RENNES 1, Rennes, France \\ ${ }^{2}$ Bostik Smart Technology Center Zac du bois de Plaisance 101, Venette, France \\ ${ }^{3}$ TOTAL S.A., Tour Michelet A, 24, Cours Michelet, La Defence, France \\ Email: *olivier.lavastre@univ-rennes1.fr
}

How to cite this paper: Colin, B., Lavastre, O., Fouquay, S., Michaud, G., Simon, F., Laferte, O. and Brusson, J.-M. (2016) Contactless Raman Spectroscopy-Based Monitoring of Physical States of Silyl-Modified Polymers during Cross-Linking. Green and Sustainable Chemistry, 6, 151-166. http://dx.doi.org/10.4236/gsc.2016.64015

Received: August 18, 2016

Accepted: October 9, 2016

Published: October 12, 2016

Copyright $\odot 2016$ by authors and Scientific Research Publishing Inc. This work is licensed under the Creative Commons Attribution International License (CC BY 4.0).

http://creativecommons.org/licenses/by/4.0/

\section{(c) (i) Open Access}

\begin{abstract}
Cross-linking of silyl-modified polymers occurs at the alkoxysilane groups attached to the ends of polymer chains by hydrolysis and polycondensation mechanisms in the presence of moisture. During these reactions, three different physical states can be identified (viscous, skin effect and cross-linked state). Knowledge of the evolution of these states at each reaction time is essential to determine the open time for the adhesive industry and is generally obtained by a manual method. Automation of this monitoring could avoid operator error and could be used for very long cross linking reactions or to screen a large number of catalysts. Thus, a contactless micro process technology was developed to correlate these physical states with an optical technology, Raman spectroscopy, by monitoring the decrease in intensity of the $\mathrm{Si}-\mathrm{OCH}_{3}$ groups during chemical reactions. This online characterization method can also be used to compare the efficiencies of several catalysts for the cross-linking of silylmodified polymers, using a minimum amount of chemical materials.
\end{abstract}

\section{Keywords}

Silyl Modified Polymers, Physical States, Micro Contactless Monitoring,

Raman Spectroscopy, Cross-Linking

\section{Introduction}

Silyl-modified polymers (SMPs) are key materials used as binders for elastic adhesives [1] [2], composites [3] [4] and electrolytes [5] and for coating [6] [7] applications. 
These hybrid polymers are also becoming increasingly common in aeronautical and aerospace applications [8]. They can be used in several other applications because of their adjustable properties [9] such as Young's modulus, tensile strength, thermal properties, gas barrier and photonic properties. Cross-linking of SMPs occurs when alkoxysilane groups attach to the ends of polymer chains via hydrolysis and polycondensation mechanisms in the presence of moisture [10] [11]. There are several intermediate states during cross-linking. Real-time monitoring of these intermediate states is essential to determine the behavior of polymers in many applications. For instance, it is crucial to know the application time (viscous state), setting time (skin effect) and time to reach maximum properties (cross-linked state) for adhesive materials.

According to the literature, several analytical methods, including ${ }^{29} \mathrm{Si}$ NMR [12], FTIR [13] and Raman spectroscopy [14]-[16] have been used to characterize the intermediate products formed during the hydrolysis and condensation reactions of alkoxysilanes.

Herein, we report on a contactless method based on Raman spectroscopy to characterize the different physical states obtained during cross-linking of different SMP.

\section{Experimental}

\subsection{Adhesive Materials}

Silyl modified polymers are silane-based chemicals that contain inorganic and organic parts and form new high-performance sealant polymers. Two silyl-terminated prepolymers were used for this study, SMP1 and SMP2, which were obtained from BOSTIK. SMP1 is a dimethoxysilane-based polyether with a urethane moiety in Figure 1(a), and SMP2 is a trimethoxysilane-based polyurethane in Figure 1(b).

\subsection{Chemical Products}

Tertiary amine catalysts: 1, 8-Diazabicyclo [5.4.0] undec-7-ene (DBU, 98\% wt), 1, 5 Diazabicyclo [4.3.0] non-5-ene (DBN, 98\% wt) and triethylamine (TEA, $\geq 99 \% \mathrm{wt}$ ) were purchased from Sigma Aldrich and were used as received without further purification.

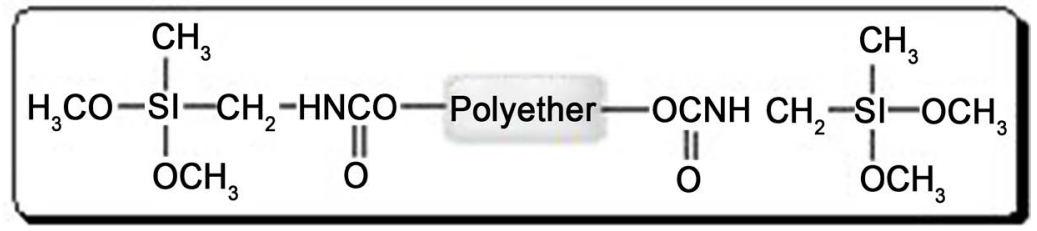

(a)

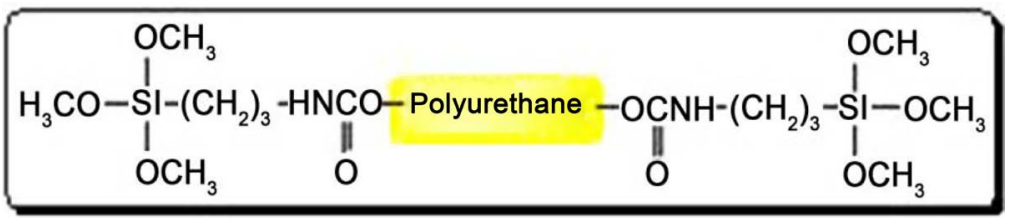

(b)

Figure 1. Scheme of silyl terminated polymers, SMP1 (a) and SMP2 (b). 
General procedure for cross-linking of SMP1 in bulk: Various rates of tertiary amine catalysts $(0.032 \mathrm{mmol}$ to $0.32 \mathrm{mmol})$ were added to SMP1 (10 g) in a plastic cup (diameter $50 \mathrm{~mm}$ and height $30 \mathrm{~mm}$ ). The mixture was stirred during 1 minute under argon. The reaction begins when mixture is in contact of moisture to allow the crosslinking.

Conditions in the room are $55 \% \mathrm{H}_{2} \mathrm{O}(+/-5 \%)$ at $23^{\circ} \mathrm{C}\left(+/-1^{\circ} \mathrm{C}\right)$, and cross-linking rate is followed by Raman spectroscopy.

General procedure for cross-linking of SMP2 in bulk: 1, 8-Diazabicyclo [5.4.0] undec-7-ene (DBU) $(0.32 \mathrm{mmol})$ was added to SMP2 $(10 \mathrm{~g})$ in a plastic cup (diameter 50 $\mathrm{mm}$ and height $30 \mathrm{~mm}$ ). The mixture is stirred during 1 minute under argon. The reaction begins when mixture is in contact of moisture to allow the cross-linking. Conditions in the room are $55 \% \mathrm{H}_{2} \mathrm{O}(+/-5 \%)$ at $23^{\circ} \mathrm{C}\left(+/-1^{\circ} \mathrm{C}\right)$, and cross-linking rate is followed by Raman spectroscopy.

\subsection{Raman Instrumentation}

Raman spectra were collected with LabRAM HR 800 (Jobin-Yvon) with a $632.8 \mathrm{~nm}$ from an $\mathrm{He}-\mathrm{Ne}$ laser and equipped with a confocal microscope. Detection was achieved with an air cooled CCD detector and a grating 600 grooves/mm, giving a spectral resolution of $4 \mathrm{~cm}^{-1}$. Before recording the spectrum of a new sample, the calibration of the spectrometer is checked by using the peak at $521 \mathrm{~cm}^{-1}$ of the silicon sample. For our study, a $100 \mathrm{x}$ objective was used to focus the surface of the mixture containing silyl modified polymers and catalyst in the $100-3600 \mathrm{~cm}^{-1}$ region and more preferably in $400-750 \mathrm{~cm}^{-1}$ region. The slit and hole parameters were respectively fixed at $125 \mu \mathrm{m}$ and $1100 \mu \mathrm{m}$. The time required to measure one spectrum was $1 \mathrm{~min}$ decomposed with an acquisition time of 30 seconds and 2 accumulations. This acquisition was repeated during 1 hour for SMP1 and 2 hours for SMP2 in order to follow the evolution of $\mathrm{Si}-\mathrm{OCH}_{3}$ groups during the hydrolysis and polycondensation reactions. The measurements were performed at $23^{\circ} \mathrm{C}\left(+/-1^{\circ} \mathrm{C}\right)$, and moisture ratio at $55 \% \mathrm{H} 2 \mathrm{O}(+/-5 \%)$. Initial spectrums of each silyl modified prepolymer (SMP1 and SMP2) without catalyst were performed in order to determine the initial intensity of $\mathrm{Si}-\mathrm{OCH}_{3}$ before the cross-linking. In the same way, spectrums of each cross-linked silyl modified polymers (SMP1 and SMP2 aged of 3 month) were performed to determine the final intensity of $\mathrm{Si}-\mathrm{OCH}_{3}$ groups. All spectra were baseline corrected before the integration with the software LabSpec v4.04. The integration was performed with following parameters: $\mathrm{w}$ (FWHM = full-width half maximum) fixed at 15 and gaussien/lorentzien ratio equal to 0.5. After the automatical fitting procedure, the area or intensity of $\mathrm{Si}-\mathrm{OCH}_{3}$ peak can be used to follow the tendency of chemical reaction. Results with area and intensity give the same results due to high resolution of Raman spectra. However, fitting procedure based on intensity of peaks was faster than fitting procedure based on area of peaks (approximately 5 to 10 times in our case). Thus, in order to quickly compare and to evaluate in real time the physical states (viscous, skin effect or gum aspect) samples containing different mixture of catalysts to determine were analyzed. 


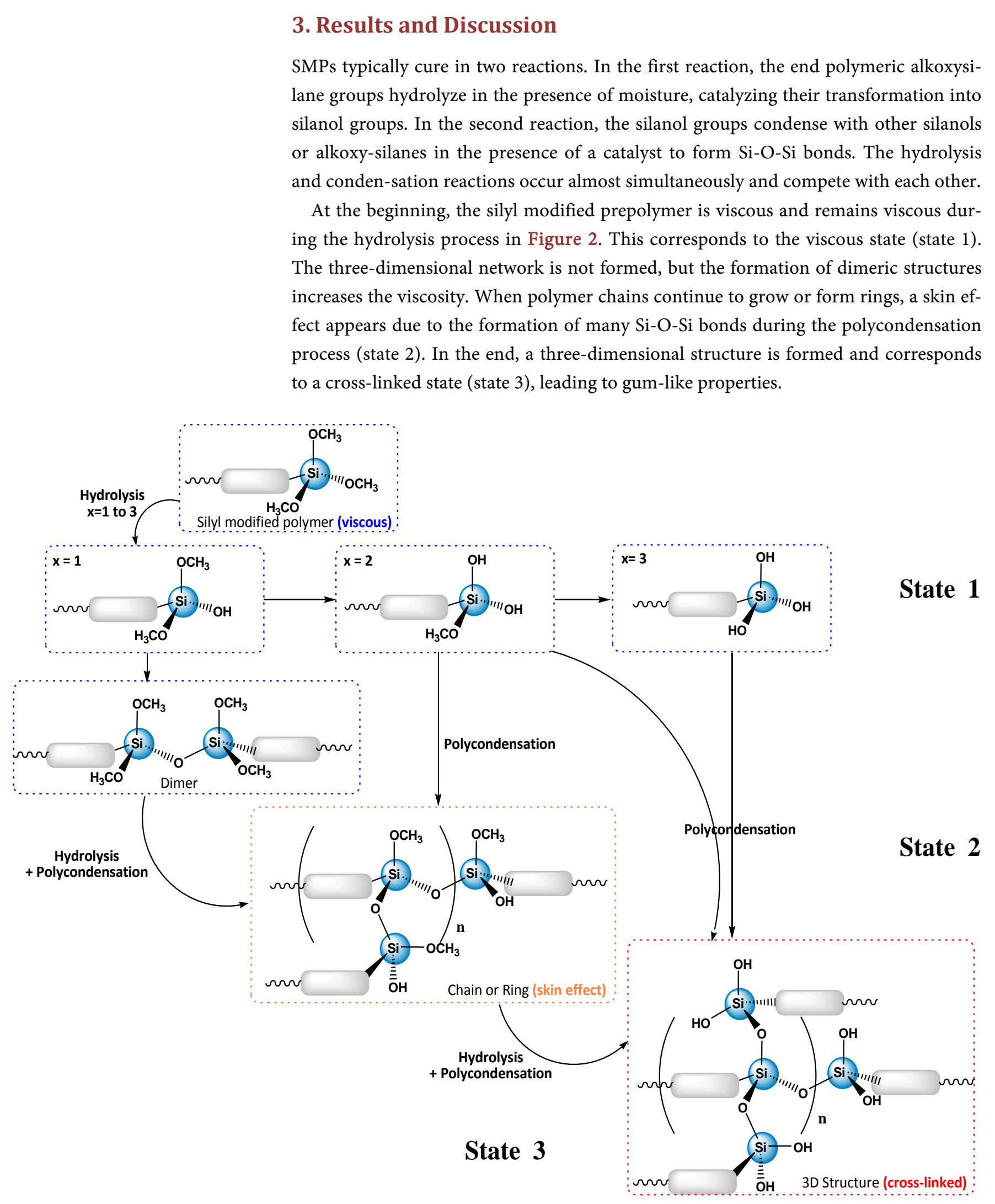

Figure 2. Scheme of different states between hydrolysis and condensation: viscous, skin effect and cross-linked state. 


\subsection{Development of the Raman Method}

\subsubsection{Selection of Peaks Corresponding to the Cross-Linking Reaction}

The key point for any Raman approach is to ensure that the correct peak is monitored, which depends on the chemical groups involved in the reaction. The first step consists of determining which peaks are associated with the hydrolysis or condensation reactions during the cross-linking of SMPs.

The Raman spectra of pure SMP1 without a catalyst in Figure 3(a) a cross-linked.

SMP1 with $0.5 \mathrm{wt} \%$ DBU in Figure $3(\mathrm{~b})$ in the $100-3600 \mathrm{~cm}^{-1}$ region, and both materials in the $400-750 \mathrm{~cm}^{-1}$ region in Figure 4 are shown. These Raman spectra demonstrate the differences between the initial state with no cross-linkage and the crosslinked end state.

Therefore, the frequencies, relative intensities and tentative assignments of the observed Raman bands for cross-linked SMP1 with $0.5 \mathrm{wt} \%$ DBU catalyst and the initial state of SMP1 are summarized in Table 1.

Both spectra have very similar features because they share the same polymer backbone. Most of the peaks from 800 to $3000 \mathrm{~cm}^{-1}$ were assigned based on several studies [17]-[20] and on the book by Socrates about Infrared and Raman Characteristic Group Frequencies [21]. As a reminder, SMP1 is a dimethoxysilane-based polyether with a urethane moiety. Several peaks correspond to $\mathrm{C}-\mathrm{O}-\mathrm{C}$ and $\mathrm{N}-\mathrm{C}$ vibrations, respectively, at $1250 \mathrm{~cm}^{-1}$ and $1370 \mathrm{~cm}^{-1}$.

The observation of alkoxysilane groups is difficult because SMP1 contains only a few percent of dimethoxysilane end groups (approximately $3 \mathrm{wt} \%$ ). Thus, it is necessary to

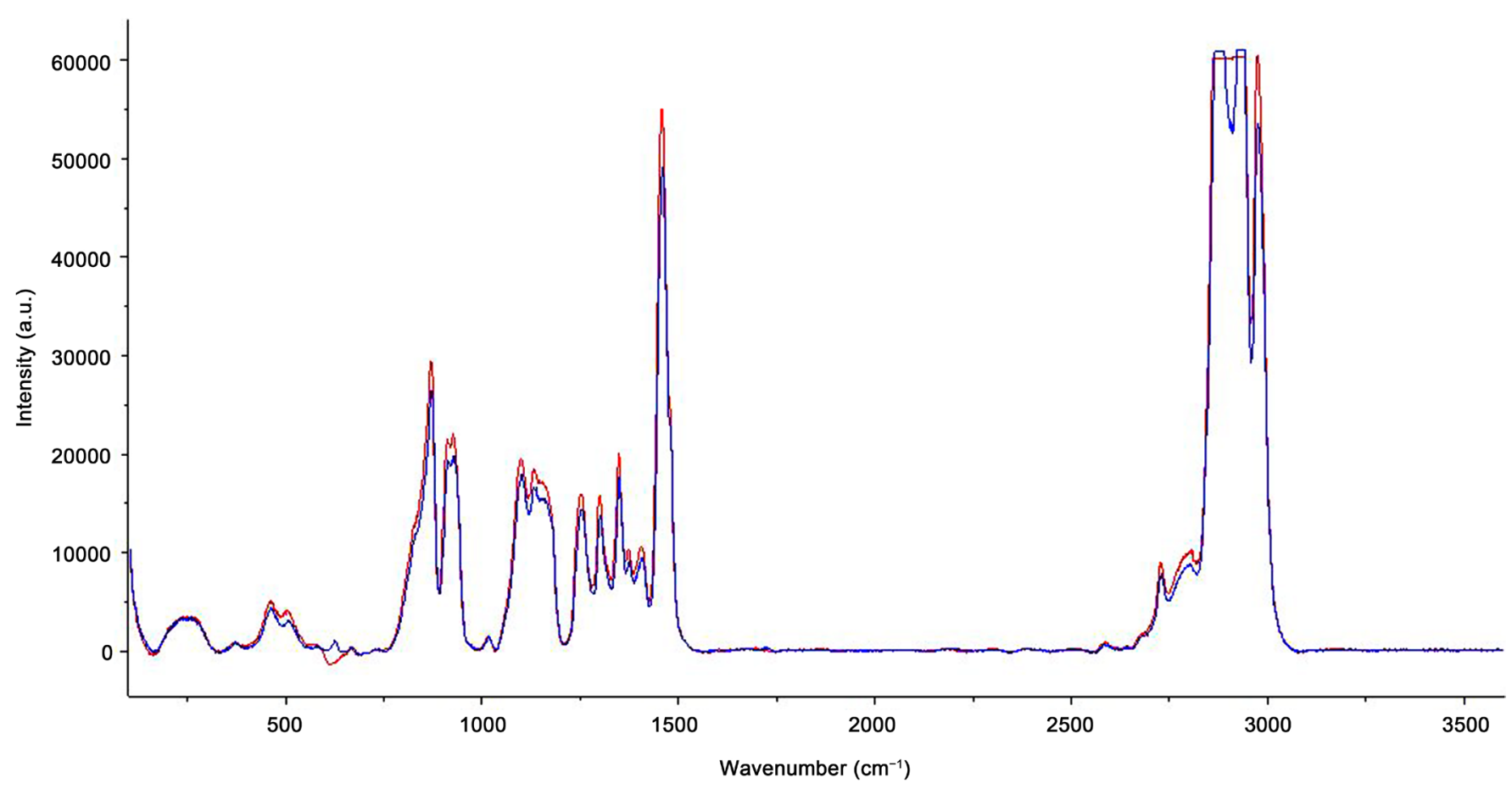

Figure 3. Raman spectra of ( $\mathrm{a}$ in blue) pure SMP1 without catalyst and (b in red) cross-linked SMP1 with $0.5 \%$ of DBU, in the $100-3600$ $\mathrm{cm}^{-1}$ region. 


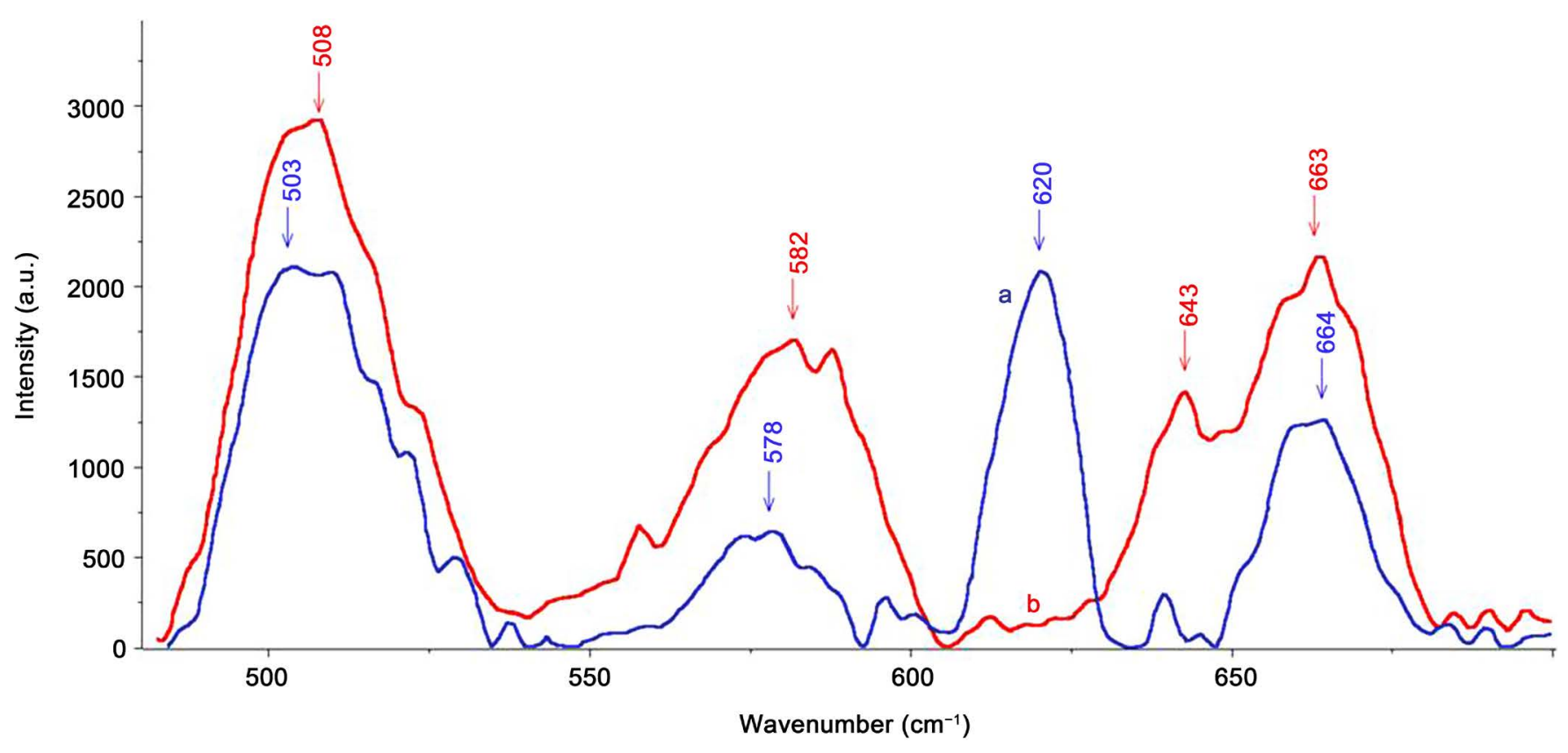

Figure 4. Raman spectra of (a in blue) pure SMP1 without catalyst and (b in red) cross-linked SMP1 with 0.5\% of DBU, in the $400-750$ $\mathrm{cm}^{-1}$ region.

Table 1. Raman spectral frequencies of initial and cross-linked SMP1 and suggested assignments ${ }^{*}=$ peaks of cross-linked SMP1 and ${ }^{+}=$ initial SMP1). Abbreviations: s, strong; m, moderate; w, weak; vw, very weak, stretch; deformation, twist; subscript s, symmetric; subscript a, asymmetric.

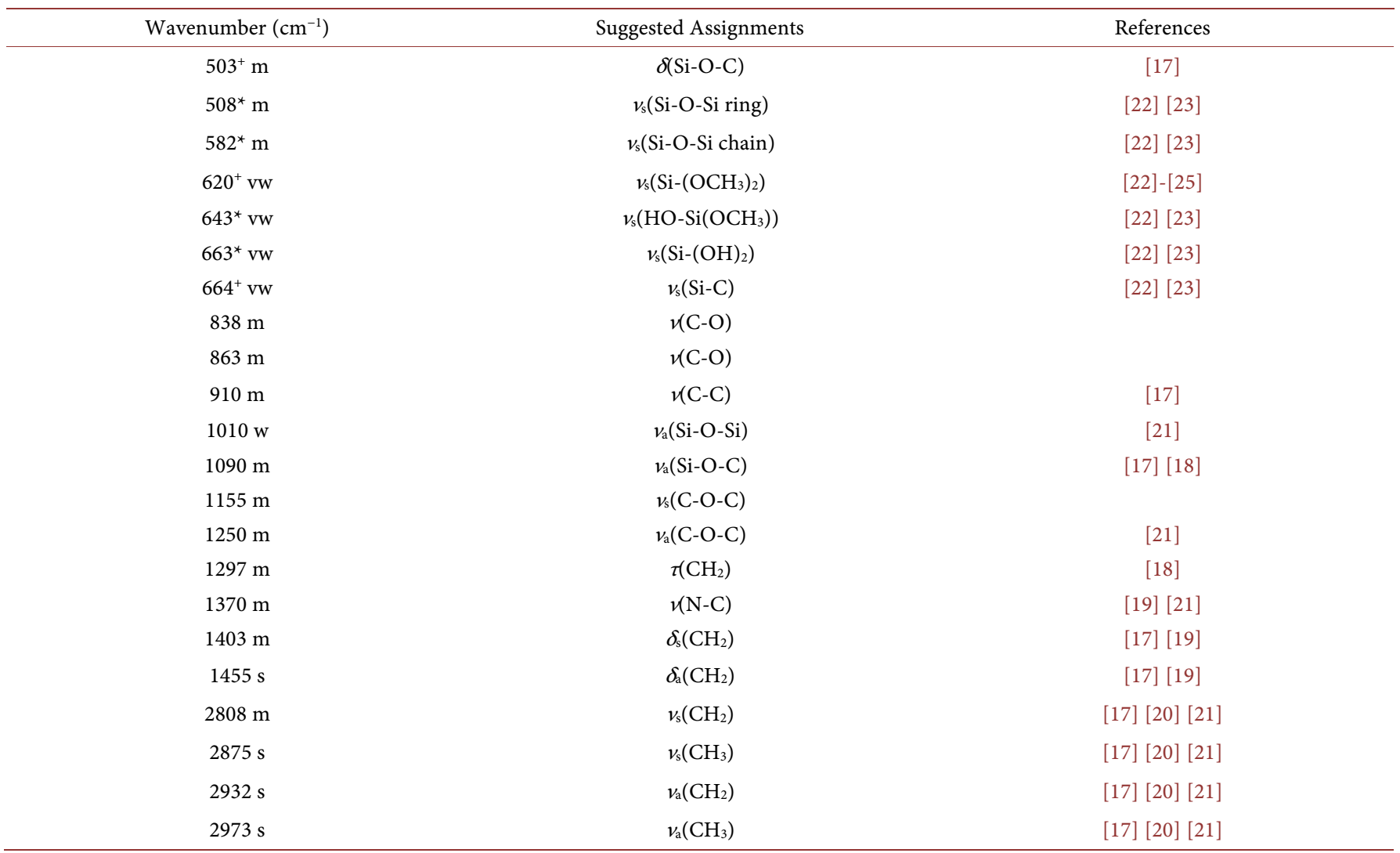


zoom in on the $400-750 \mathrm{~cm}^{-1}$ region to observe the differences between the two states (cross-linked and no cross-linked). We referred to vibrational spectroscopic studies of compounds containing alkoxysilane groups such as methylmethoxysilanes [22], tetramethyl orthosilicate (TMOS) or tetraethyl orthosilicate (TEOS) [23], glycidoxypropyltrimethoxysilane (GPTS)/amiopropyltriethoxysilane (APTS) systems [24] and silica aerogels [25]. As described in these studies, $\mathrm{Si}-\mathrm{O}-\mathrm{Si}$ vibrations could be assigned to the $500-600 \mathrm{~cm}^{-1}$ region.

In addition, different structures of $\mathrm{Si}-\mathrm{O}-\mathrm{Si}$ bonds can be formed in intermediate products by polycondensation reactions. Indeed, many condensed structures (chain, branched and ring) can be formed due to the large number of active sites available per silicon atom. However, the peak at $620 \mathrm{~cm}^{-1}$ is only present in the SMP1 without crosslinkage and gradually decreases during the cross-linking reaction. Thus, this peak is characteristic of the symmetric $\mathrm{Si}-\left(\mathrm{OCH}_{3}\right)_{2}$ vibration, corresponding to the first reactive groups susceptible to reaction during the hydrolysis step. Moreover, the peaks at 643 and $663 \mathrm{~cm}^{-1}$ are only found in the cross-linked product and directly shift to higher wave numbers compared to the peaks in Si- $\left(\mathrm{OCH}_{3}\right)_{2}$. We suggest that the peaks at 643 and $663 \mathrm{~cm}^{-1}$ represent the intermediate products at different degrees of hydrolysis $(\mathrm{x}=$ 1 at $643 \mathrm{~cm}^{-1}$ and $\mathrm{x}=2$ at $\left.663 \mathrm{~cm}^{-1}\right)$.

\subsubsection{Monitoring of Si-(OR) Groups}

The most adaptive peak should be used to follow the cross-linking reaction and characterize the three physical states (viscous, skin effect and cross-linked states). We expect to see a decrease in the peak at $620 \mathrm{~cm}^{-1}$ during the hydrolysis step and the increase in the peak of Si-O-Si groups at $500-600 \mathrm{~cm}^{-1}$ during the polycondensation reaction. A mixture of SMP1 and 0.5 wt\% of DBU catalyst was monitored by Raman spectroscopy to determine the evolution of the alkoxysilane groups during the cross-linking reaction in Figure 5.

As expected, we noted a decrease in the intensity of the $\mathrm{Si}-\left(\mathrm{OCH}_{3}\right)_{2}$ groups at 620 $\mathrm{cm}^{-1}$, the formation of Si-O-Si bonds at $583 \mathrm{~cm}^{-1}$ and an increase in the intensity of the peaks at 643 and $663 \mathrm{~cm}^{-1}$. Thus, there are still Si- $(\mathrm{OH})$ groups after 1 hour of reaction, indicating that the polymer is not fully cured after 1 hour. Moreover, some silyl-modified polymers require several days to achieve complete cross-linking because of the slow diffusion of water into a three-dimensional structure.

As mentioned previously, hydrolysis and condensation reactions occur simultaneously and depend on experimental conditions such as the nature and concentration of the hydrolyzable groups, temperature and $\mathrm{pH}$ values. Indeed, for a sol-gel process of alkoxysilane in aqueous solution [26] [27], the kinetics of the hydrolysis and condensation reactions are generally controlled by the $\mathrm{pH}$ of the solution. Under acidcatalyzed conditions, the hydrolysis kinetics are favored over condensation, which starts when hydrolysis is completed. For instance, if the $\mathrm{pH}$ value changes from 7 (the rate is minimal) to 6 , the rate constant is multiplied by 10 . In base-catalyzed conditions, condensation is faster than hydrolysis, resulting in a highly $3 \mathrm{D}$ condensed structure. In our case, with $\mathrm{DBU}$ as a catalyst, the decrease in $\mathrm{Si}-\left(\mathrm{OCH}_{3}\right)_{2}$ groups is a direct characteristic 


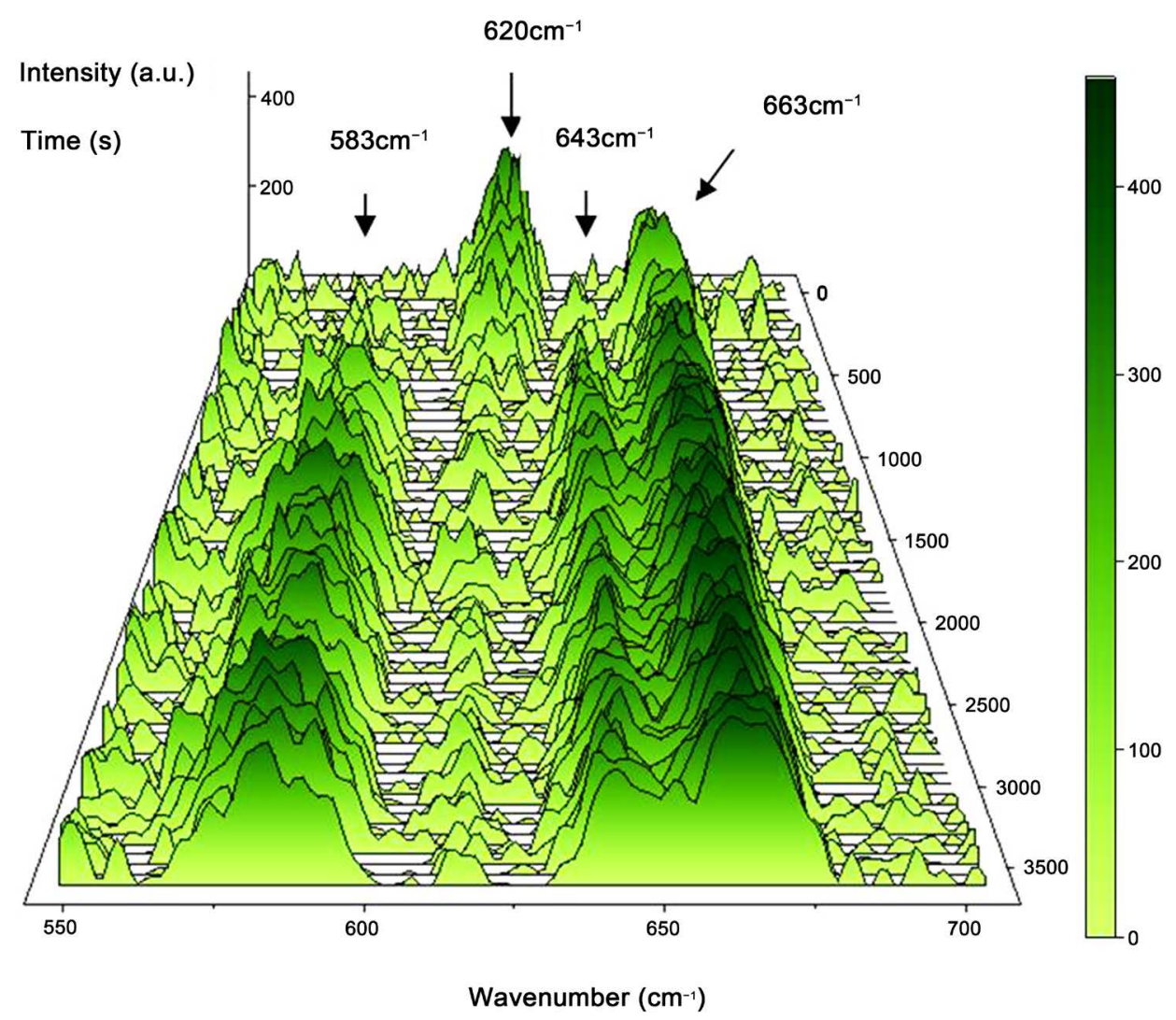

Figure 5. Series of Raman spectra of SMP1 during hydrolysis and condensation reactions (0 to1 h) in $550-700 \mathrm{~cm}^{-1}$ region.

of the cross-linking reaction. Thus, this peak seems to be the best spectroscopic probe to follow the cross-linking reaction.

\subsubsection{Quantification of Si- $\left(\mathrm{OCH}_{3}\right)$ Groups}

Cross-linking of SMP1 catalyzed with different ratios of DBU $(0.05,0.1,0.3$ and 0.5 wt\%) was monitored, and the Raman intensities of the $\mathrm{Si}-\left(\mathrm{OCH}_{3}\right)_{2}$ groups at $620 \mathrm{~cm}^{-1}$ were plotted against time in Figure 6.

The analysis was repeated three times for each catalyst ratio in order to determine the reproducibility of the results.

The reaction time decreases when the rate of catalysis increases. Indeed, by using 0.5 wt\% DBU, a cross-linked structure (corresponding to the complete disappearance of $\mathrm{Si}-\left(\mathrm{OCH}_{3}\right)_{2}$ groups $)$ is obtained after only 15 to 20 minutes; whereas, with $0.05 \mathrm{wt} \%$ catalyst more than 30 minutes is necessary to observe the total disappearance of the $\mathrm{Si}-\left(\mathrm{OCH}_{3}\right)_{2}$ groups. These results are reproducible as the deviation between the two experiments was lower than $10 \%$ for each value. The monitoring of the $\mathrm{Si}-\left(\mathrm{OCH}_{3}\right)$ intensity allowed for fast and online monitoring of the cross-linking reaction.

\subsection{Correlation with the Standard Method}

The second step of this study was to correlate the results obtained by Raman spectro- 


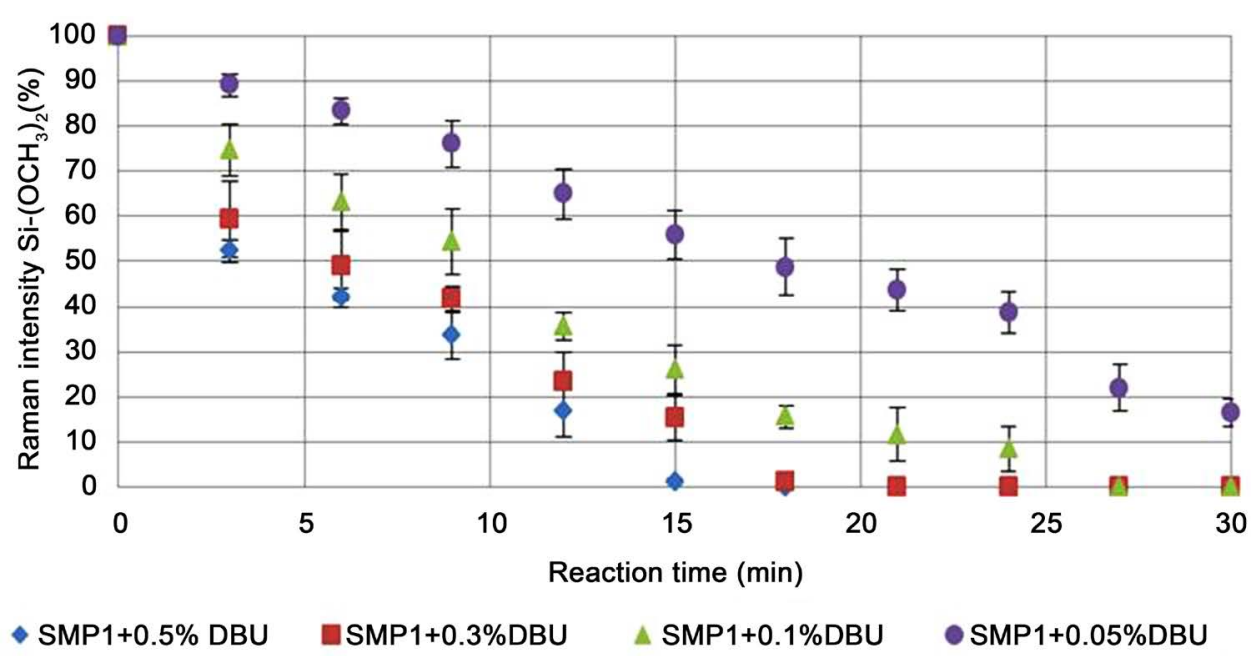

Figure 6. Raman intensity of $\mathrm{Si}-\left(\mathrm{OCH}_{3}\right)_{2}$ groups during cross-linking of SMP1 catalyzed with different rate of DBU $(0.05 ; 0.1 ; 0.3$ and $0.5 \% \mathrm{wt})$.

scopy with the physical states observed by an iterative and manual method already described by BOSTIK [28]. This method requires an operator to touch the surface of the mixture (SMP + catalyst) with a needle during the cross-linking reaction to determine the physical states: viscous, skin effect or cross-linked in Figure 7. Characteristic times for the appearance of these states were measured using this standard method at different ratios of DBU (Table 2).

This classical method is efficient but time-consuming and does not allow for an accurate comparison of a large number of mixtures. In addition, this method is based on a visual aspect and is operator dependent. Thus, it was interesting to determine the physical states directly from Raman analysis by monitoring the chemical evolution of the alkoxysilane groups. Indeed, the levels of Raman intensity at $620 \mathrm{~cm}^{-1}$ were determined for each state during the curing process of SMP1. An intensity of $100 \%$ corresponds to the initial intensity at $620 \mathrm{~cm}^{-1}$ for the $\mathrm{Si}-\left(\mathrm{OCH}_{3}\right)_{2}$ groups at the beginning of the reaction, and $0 \%$ Raman intensity at $620 \mathrm{~cm}^{-1}$ corresponds to an SMP sample aged for 3 months. We observed that for Raman intensities between $100 \%$ and $60 \%$, the physical state of the mixture is viscous; for Raman intensities between $60 \%$ and $25 \%$, the skin effect occurs; and below 25\%, a cross-linked product is obtained. For a fast and easy correlation between the Raman intensity and the physical state of the sample, we attributed blue color to the intensity level between $100 \%$ and $60 \%$, corresponding to the viscous state; orange color to the intensity level between $60 \%$ and $25 \%$, corresponding to the skin effect; and red color to the intensity level below $25 \%$, corresponding to a cross-linked gum state in Figure 8.

This spectroscopic method allows for fast detection of the physical states of SMP1 at any time. In addition, the color assigned to each state could be key for easily establishing the open time for this adhesive. For example, when the polymer is viscous (blue, Raman intensity higher than 60\%) and until the appearance of the skin effect (orange, Raman intensity between $60 \%$ and $25 \%$ ), an adhesive can be easily repositioned on a 


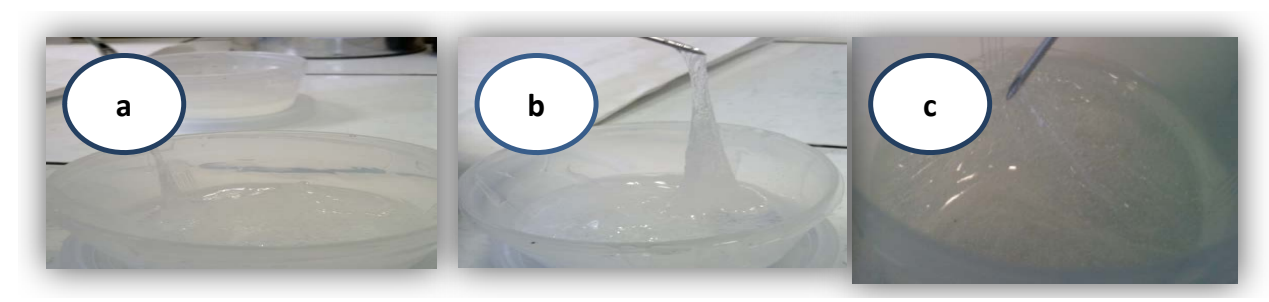

Figure 7. Pictures representing the interaction between the surface of polymer and a needle during cross-linking reaction, (a) viscous to skin effect, (b) skin effect and (c) skin effect to crosslinked gum aspect.

Table 2. Measurements of characteristic times for each physical state were taken using the operator standard method for four mixtures containing different ratios of DBU catalyst. State a) corresponds to the transition from viscous to skin effect, state b) is the skin effect state, and state c) is the transition from skin effect to cross-linked structure, and, finally, the time to reach a gumlike state.

\begin{tabular}{ccccc}
\hline DBU\% wt & State a $(\min )$ & State b $(\min )$ & State c (min) & Cross-linked $(\min )$ \\
\hline 0.05 & $8^{\prime}$ & $11^{\prime}$ & $14^{\prime}$ & $29^{\prime}$ \\
0.1 & $5^{\prime} 45$ & $7^{\prime} 45$ & $10^{\prime} 30$ & $19^{\prime}$ \\
0.3 & $3^{\prime} 30$ & $5^{\prime}$ & 6 & $11^{\prime}$ \\
0.5 & $2^{\prime} 30$ & $3^{\prime} 45$ & $4^{\prime} 45$ & $8^{\prime}$ \\
\hline
\end{tabular}

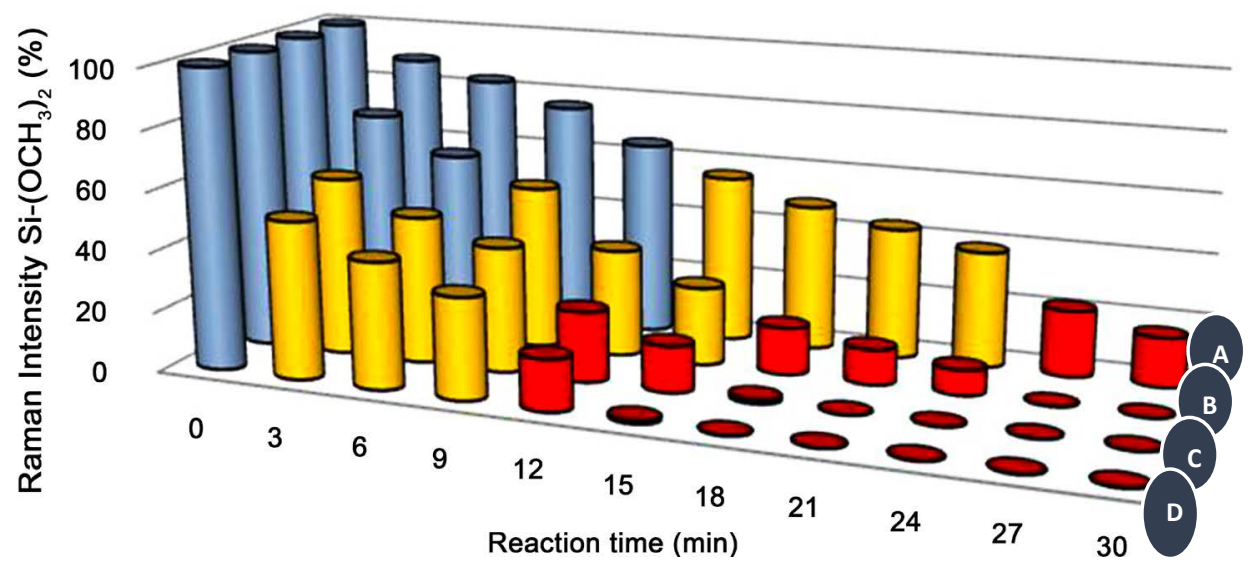

Figure 8. Raman intensity of $\mathrm{Si}-\left(\mathrm{OCH}_{3}\right)_{2}$ from SMP1 catalyzed with 0.05 to $0.5 \%$ wt DBU (A to D) and correlation with physical states, blue $=$ viscous, orange $=$ skin effect and red $=$ crosslinked.

support. Then, when the polymer is cross-linked (red, Raman intensity lower than $25 \%)$, the support containing the adhesive can be manipulated without any risk of disbonding.

\subsection{Extension of the Contactless Raman Method}

Different intermediate products can be obtained depending on the type of catalyst used and whether the conditions are basic or acidic, allowing cross-linking of silyl modified 
polymers. Indeed, strong acids such as $\mathrm{CF}_{3} \mathrm{SO}_{3} \mathrm{H}$ [29] or $\mathrm{HCl}$ [30] efficiently accelerate the process of hydrolysis. Under basic conditions, hydroxyl $\left(\mathrm{OH}^{-}\right)$ions attack the most positively charged atom by nucleophilic reaction [31]. Super-bases such as DBU or TBD are very efficient at accelerating the reaction and increasing the density of cross-linking [32]. Thus, Raman spectroscopy seems to be an ideal technique for screening different catalysts to determine their catalytic effect on the hydrolysis [33] [34] and polycon-densation steps because the analysis is rapid and can be performed in situ for different SMPs.

\subsubsection{Study with Different Catalysts for SMP1 Cross-Linking}

This method was applied to compare the cross-linking activity of several basic catalysts (DBU, DBN and $\mathrm{NEt}_{3}$ ) on SMP1 in Figure 9. The Raman intensity levels and their colors which were previously determined were directly applied to observe the different physical states of SMP1.

The physical states measured with DBU and DBN seem identical because of the relatively identical structure of these two catalysts. We noted that $\mathrm{NEt}_{3}$ was not efficient for cross-linking of SMP1 after 30 minutes of reaction with moisture. The different efficiencies of these catalysts can be explained by their pKa values. In fact, only super bases such as DBU or DBN are really active. The very high basicities of DBU and DBN (pKa at 12) [35] compared to $\mathrm{NEt}_{3}$ ( $\mathrm{pKa}$ at 10,75) [36] are induced by the amidinium stabilization and seem to be a key point for high catalytic activity.

Furthermore, the application of this method can be an efficient way to quickly screen catalytic systems on SMP1 and obtain the corresponding open times (time window for repositioning of the sample or time before the sample can be used), which are key parameters for the adhesive industry.

\subsubsection{Study of SMP2 Cross-Linking}

This method was also applied to another SMP called SMP2, which is a trimethoxysilane-based polyurethane as described in Figure 1 Cross-linking reactions between SMP1 and SMP2 are very different because of the molecular structure of the terminal

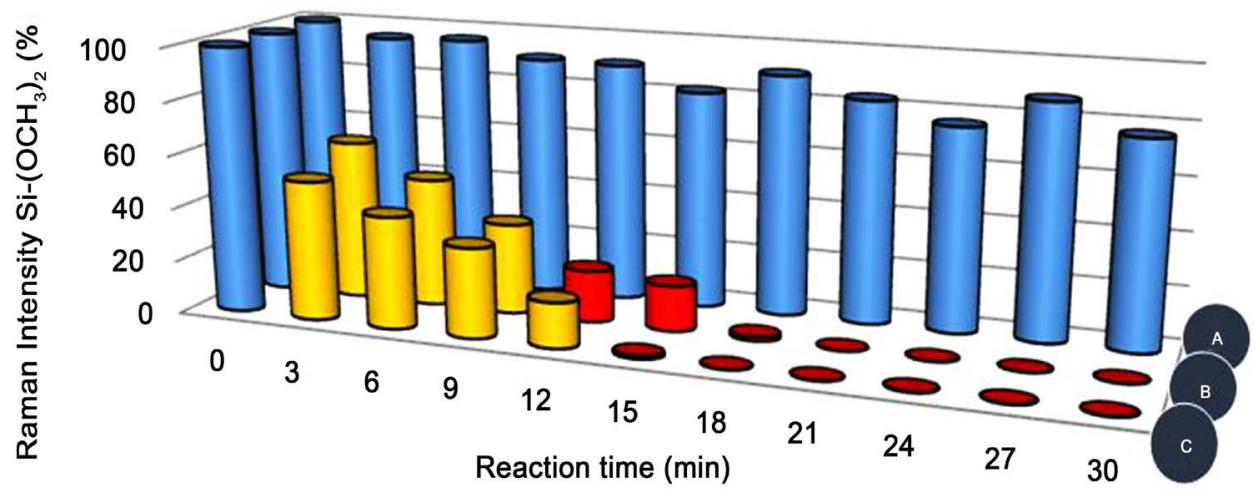

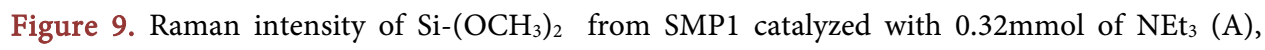
$\mathrm{DBN}(\mathrm{B})$, and DBU (C) and correlation with physical states, blue = viscous, orange = skin effect and red $=$ cross-linked. 
silyl groups. In the case of urethane-dimethoxysilane (SMP1), the electron donor (nitrogen atom with a free electron pair) is attached to a silicon atom via one methylene group as a spacer. Additionally, the methyl group attached to the silicon atom can play an important role through an inductive effect. Indeed, the electron density is shifted to the silicon atom, and the $\mathrm{Si}-\left(\mathrm{OCH}_{3}\right)$ bond is weakened. In this case, the cross-linking reaction time decreases because of the activation of the alkoxide group. Therefore, the alkoxide groups split off more easily, and hydrolysis is accelerated. However, the cross-linking time of SMP2, which is terminated with trimethoxysilane, is slower than that of SMP1 because there is no alkoxide group activation (nitrogen atom attached to silicon via a propylene group as a spacer). It is well known that the Raman shift may depend on the environment of a group of atoms and their position in a prepolymer or polymer network. That is why it is necessary to determine the peak characteristics of the $\mathrm{Si}-\left(\mathrm{OCH}_{3}\right)$ groups in SMP2 in Figure 10.

The peak at $644 \mathrm{~cm}^{-1}$ represents the $\mathrm{Si}-\left(\mathrm{OCH}_{3}\right)_{3}$ groups in the trifunctionnal prepolymer (SMP2). The shift of these bands is different from that seen in SMP1 (620 to 644 $\mathrm{cm}^{-1}$ ) and is probably due to the difference in the chemical environment of each polymer backbone: polyether (SMP1) and polyurethane (SMP2). A correlation between the cross-linking reaction and physical properties was also established for SMP2 by monitoring the decrease in the intensity of the $\mathrm{Si}-\left(\mathrm{OCH}_{3}\right)_{3}$ peaks at $644 \mathrm{~cm}^{-1}$. New Raman intensity levels were determined and correlated with each physical state. The levels are characteristic of each prepolymer because of their different structures. For SMP2, the Raman intensities between $100 \%$ and $50 \%$ indicate that the mixture is viscous, those between $50 \%$ and $20 \%$ indicate that the skin effect occurs, and those below $20 \%$ indicate that a cross-linked product is obtained (Figure 11).

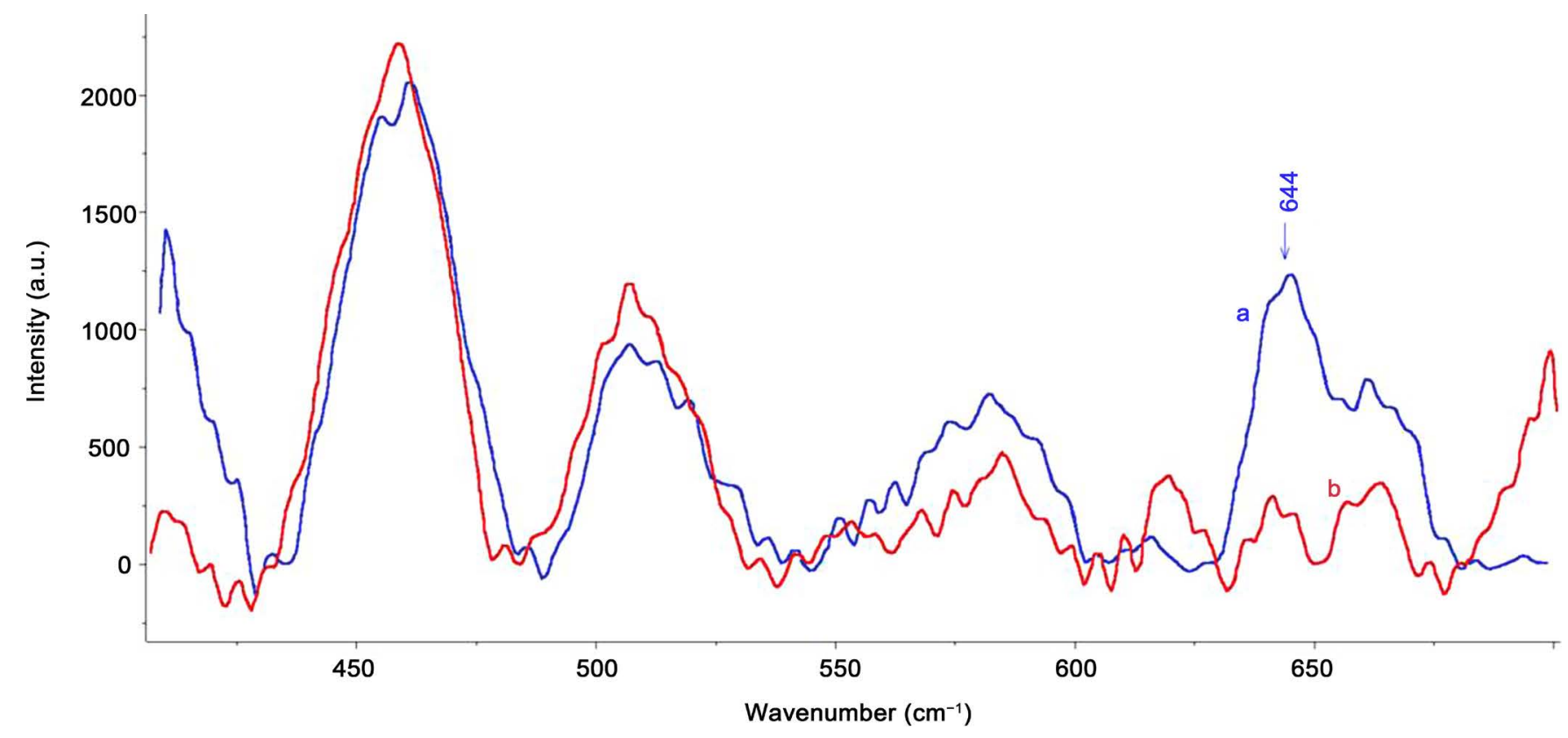

Figure 10. Raman spectra of (a in blue) pure SMP2 without catalyst and (b in red) cross-linked SMP2 with $0.5 \%$ of DBU, in the $400-700$ $\mathrm{cm}^{-1}$ region. 


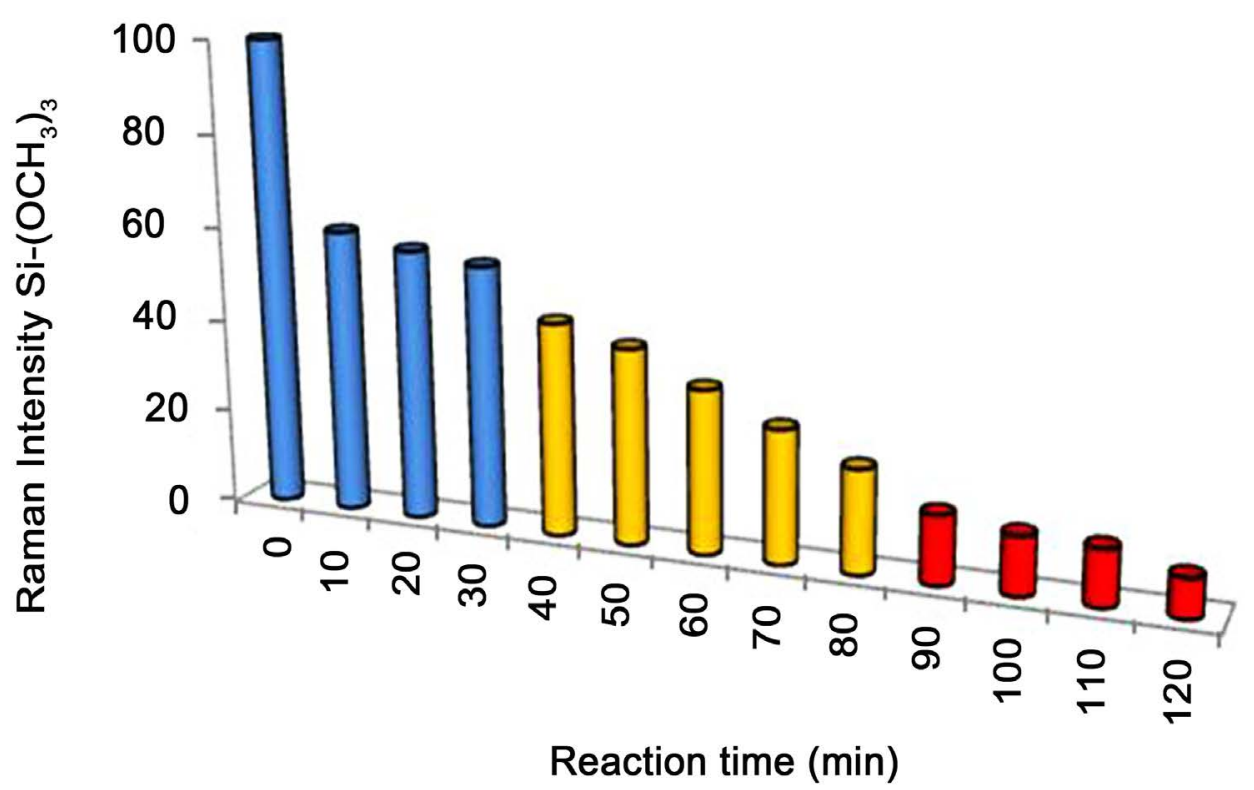

Figure 11. Raman intensity of $\mathrm{Si}-\left(\mathrm{OCH}_{3}\right)_{3}$ from SMP2 catalyzed with $0.5 \%$ wt DBU catalyst and correlation with physical states, blue $=$ viscous, orange $=$ skin effect and red $=$ cross-linked.

This result indicates that our method can be applied to different SMPs by determining the peak that corresponds to the alkoxysilane end groups and allows for fast detection of physical states at any time without the manual intervention of an operator. Based on this, this method could be useful for analyzing SMPs that have higher crosslinking times (several hours or several days).

\section{Conclusions}

An original spectroscopic method was developed to characterize the physical states of SPM prepolymers during moisture curing. The Raman intensity of the alkoxysilane groups allows for quick determination of the physical states, viscous, skin effect and cross-linked, with good reproducibility. This method is an attractive and efficient way to characterize the physical state and determine the open time for the adhesive industry.

Thanks to commercially available miniaturized Raman spectrometer, one can envision to apply this non-contact optical method for on line or on site applications for adhesives. Furthermore, an approach that combines micro-reactor technology with fiber-optic Raman spectroscopy was already described for the performance of real-time measurements [37]. Based on our recent study on the development of a semi-quantitative high-throughput screening (HTS) method to compare and detect efficient catalysts for adhesive materials [38], we can envisage coupling the HTS approach with the Raman method developed in this study to create a powerful quantitative method. This method could be used to detect new catalysts for adhesive materials with specific time windows for applications such as repositionable samples or samples that are ready to use after a specific time for irreversible adhesion. 


\section{Acknowledgements}

The authors gratefully acknowledge CNRS, ANRT, BOSTIK and TOTAL for their financial support.

\section{References}

[1] Maudgal, S. and St. Clair, T.L. (1984) Preparation and Properties of Silane-Endcapped Polyimide Adhesives. International Journal of Adhesion and Adhesives, 4, 129-132. http://dx.doi.org/10.1016/0143-7496(84)90014-9

[2] Huang, H.H. and Wilkes, G.L. (1989) Structure-Property Behaviour of Hybrid Materials Incorporating Tetraethoxysilane with Multifunctional Poly(tetramethylene oxide). Polymer, 30, 2001-2012. http://dx.doi.org/10.1016/0032-3861(89)90286-3

[3] Liu, P., Song, J., He, L., Liang, X., Ding, H. and Li, Q. (2008) Alkoxysilane Functionalized Polycaprolactone/Polysiloxane Modified Epoxy Resin through Sol-Gel Process. European Polymer Journal, 44, 940-951. http://dx.doi.org/10.1016/j.eurpolymj.2007.12.014

[4] Serier, A., Pascault, J.P. and Lam, T.M. (1991) Reactions in Aminosilane-Epoxy Prepolymer Systems. II. Reactions of Alkoxysilane Groups with or without the Presence of Water. Journal of Polymer Science Part A: Polymer Chemistry, 29, 1125-1131. http://dx.doi.org/10.1002/pola.1991.080290806

[5] Saikia, D., Wu, C.G., Fang, J., Tsai, L.D. and Kao, H.M. (2014) Organic-Inorganic Hybrid Polymer Electrolytes Based on Polyether Diamine, Alkoxysilane, and Trichlorotriazine: Synthesis, Characterization, and Electrochemical Applications. Journal of Power Sources, 269, 651-660. http://dx.doi.org/10.1016/j.jpowsour.2014.06.159

[6] Schmidt, H. and Seiferling, B. (1986) Chemistry and Applications of Inorganic-Organic Polymers (Organically Modified Silicates). Materials Research Society Symposium Proceedings, 73, 739-750. http://dx.doi.org/10.1557/PROC-73-739

[7] Alyamac, E., Gu, H., Soucek, M.D., Qiu, S. and Buchheit, R.G. (2012) Alkoxysilane Oligomer Modified Epoxide Primers. Progress in Organic Coatings, 74, 67-81.

http://dx.doi.org/10.1016/j.porgcoat.2011.11.012

[8] Maleki, H., Duraes, L. and Portugal, A. (2014) An Overview on Silica Aerogels Synthesis and Different Mechanical Reinforcing Strategies. Journal of Non-Crystalline Solids, 385, 55-74. http://dx.doi.org/10.1016/j.jnoncrysol.2013.10.017

[9] Alexandre, M. and Dubois, P. (2000) Polymer-Layered Silicate Nanocomposites: Preparation, Properties and Uses of a New Class of Materials. Materials Science and Engineering, 28, 1-63. http://dx.doi.org/10.1016/S0927-796X(00)00012-7

[10] Surivet, F., Lam, T.M., Pascault, J.P. and Pham, Q.T. (1992) Organic-Inorganic Hybrid Materials. 1. Hydrolysis and Condensation Mechanisms Involved in Alkoxysilane-Terminated Macromonomers. Macromolecules, 25, 4309-4320. http://dx.doi.org/10.1021/ma00043a011

[11] Schmidt, H., Scholze, H. and Kaiser, A. (1984) Principles of Hydrolysis and Condensation Reaction of Alkoxysilanes. Journal of Non-Crystalline Solids, 63, 1-11. http://dx.doi.org/10.1016/0022-3093(84)90381-8

[12] Paquet, O., Salon, M.-C.B., Zeno, E. and Belgacem, M.N. (2012) Hydrolysis-Condensation Kinetics of 3-(2-Amino-ethylamino)propyl-trimethoxysilane. Materials Science and Engineering $C$, 32, 487-493. http://dx.doi.org/10.1016/j.msec.2011.11.022

[13] Wu, C., Wu, Y., Xu, T. and Yang, W. (2006) Study of Sol-Gel Reaction of Organically Modified Alkoxysilanes. Part I: Investigation of Hydrolysis and Polycondensation of Phenylaminomethyl Triethoxysilane and Tetraethoxysilane. Journal of Non-Crystalline Solids, 352, 
5642-5661. http://dx.doi.org/10.1016/j.jnoncrysol.2006.08.037

[14] Lippert, J.L., Melpolder, S.B. and Kelts, L.W. (1988) Raman Spectroscopic Determination of the $\mathrm{pH}$ Dependence of Intermediates in Sol-Gel Silicate Formation. Journal of Non-Crystalline Solids, 104, 139-147. http://dx.doi.org/10.1016/0022-3093(88)90193-7

[15] Artaki, I., Bradley, M., Zerda, T.W. and Jonas, J. (1985) NMR and Raman Study of the Hydrolysis Reaction in Sol-Gel Processes. The Journal of Physical Chemistry A, 89, 4399-4404. http://dx.doi.org/10.1021/j100266a050

[16] Rauter, A., Perše, L.S., Orel, B., Bengü, B., Sunetci, O. and Vuk, A.S. (2013) Ex Situ IR and Raman Spectroscopy as a Tool for Studying the Anticorrosion Processes in (3-Glycidoxypropyl)Trimethoxysilane-Based Sol-Gel Coatings. Journal of Electroanalytical Chemistry, 703, 97-107. http://dx.doi.org/10.1016/j.jelechem.2013.05.015

[17] Li, Y.-S., Church, J.S., Woodhead, A.L., Vecchio, N.E. and Yang, J. (2014) Infrared and Raman Spectroscopic Studies of Tris-[3-(trimethoxysilyl)propyl] Isocyanurate, Its Sol-Gel Process, and Coating on Aluminum and Copper. Spectrochimica Acta Part A: Molecular and Biomolecular Spectroscopy, 132, 225-231. http://dx.doi.org/10.1016/j.saa.2014.04.172

[18] Li, Y.-S., Tran, T., Xu, Y. and Vecchio, N.E. (2006) Spectroscopic Studies of Trimetoxypropylsilane and Bis(Trimethoxysilyl)Ethane Sol-Gel Coatings on Aluminum and Copper. Spectrochimica Acta Part A: Molecular and Biomolecular Spectroscopy, 65, 779-786. http://dx.doi.org/10.1016/j.saa.2005.12.040

[19] Seifer, G.B. (2002) Cyanuric Acid and Cyanurates. Russian Journal of Coordination Chemistry, 28, 301-324. http://dx.doi.org/10.1023/A:1015531315785

[20] Li, Y.-S., Vecchio, N.E. and Lu, W. (2013) Infrared and Raman Spectra of (3,3,3-Trifluoropropyl)Trimethoxysilane, Its Sol and Xerogel. Spectrochimica Acta Part A: Molecular and Biomolecular Spectroscopy, 105, 213-217. http://dx.doi.org/10.1016/j.saa.2012.12.022

[21] Socrates, G. (2001) Infrared and Raman Characteristic Group Frequencies. 3rd Edition, John Wiley \& Sons, Hoboken.

[22] Bennett, M.D., Wolters, C.J., Brandstadt, K.F. and Tecklenburg, M.M.J. (2012) Raman Spectroscopy and DFT Calculations of Intermediates in the Hydrolysis of Methylmethoxysilanes. Journal of Molecular Structure, 1023, 204-211. http://dx.doi.org/10.1016/j.molstruc.2012.06.008

[23] Colomban, Ph. (1996) Raman Studies of Inorganic Gels and of Their Sol-to-Gel, Gel-toGlass and Glass-to-Ceramics Transformation. Journal of Raman Spectroscopy, 27, 747-758. http://dx.doi.org/10.1002/(SICI)1097-4555(199610)27:10<747::AID-JRS38>3.0.CO;2-E

[24] Riegel, B., Blittersdorf, S., Kiefer, W., Hofacker, S., Müller, M. and Schottner, G. (1998) Kinetic Investigations of Hydrolysis and Condensation of the Glycidoxypropyltrimethoxysilane/Aminopropyltriethoxy-Silane System by Means of FT-Raman Spectroscopy I. Journal of Non-Crystalline Solids, 226, 76-84. http://dx.doi.org/10.1016/S0022-3093(97)00487-0

[25] Riegel, B., Plittersdorf, S., Kiefer, W., Hüsing, H. and Schubert, U. (1997) Raman Spectroscopic Analysis of the Sol-Gel Processing of RSi(OMe)3Si(OMe)4 Mixtures. Journal of Molecular Structure, 410-411, 157-160. http://dx.doi.org/10.1016/S0022-2860(96)09690-1

[26] Livage, J., Henry, M. and Sanchez, C. (1988) Sol-Gel Chemistry of Transition Metal Oxides. Progress in Solid State Chemistry, 18, 259-341. http://dx.doi.org/10.1016/0079-6786(88)90005-2

[27] Livage, J. and Sanchez, C. (1992) Sol-Gel Chemistry. Journal of Non-Crystalline Solids, 145, 11-19. http://dx.doi.org/10.1016/S0022-3093(05)80422-3

[28] Patent of BOSTIK 0165453 A1 (2012).

[29] Kaddami, H., Surivet, F., Gérard, J.F., Lam, T.M. and Pascault, J.P. (1994) Hybrid Organic- 
Inorganic Materials Synthesized by Reaction with Alkoxysilanes: Effect of the Acid-to-Alkoxide Ratio on Morphology. Journal of Inorganic and Organometallic Polymers, 4, 183198. http://dx.doi.org/10.1007/BF01036542

[30] Brinker, C.J. and Scherer, G.W. (1985) Sol $\rightarrow$ Gel $\rightarrow$ Glass: I. Gelation and Gel Structure. Journal of Non-Crystalline Solids, 70, 301-322.

http://dx.doi.org/10.1016/0022-3093(85)90103-6

[31] Matsuyama, I., Satoh, S., Katsumoto, M. and Susa, K. (1991) Raman and GC-MS Study of the Initial Stage of the Hydrolysis of Tetramethoxysilane in Acid and Base Catalyzed SolGel Processes. Journal of Non-Crystalline Solids, 135, 22-28.

http://dx.doi.org/10.1016/0022-3093(91)90438-C

[32] Patent of KANEKA US 8,124,690 B2 (2012).

[33] Matos, L.C., Ilharco, L.M. and Almeida, R.M. (1992) The Evolution of TEOS to Silica Gel and Glass by Vibrational Spectroscopy. Journal of Non-Crystalline Solids, 147-148, 232237. http://dx.doi.org/10.1016/S0022-3093(05)80622-2

[34] Zhai, Q., Zhou, C., Zhao, S., Peng, C. and Han, Y. (2014) Kinetic Study of Alkoxysilane Hydrolysis under Acidic Conditions by Fourier Transform near Infrared Spectroscopy Combined with Partial Least-Squares Model. Industrial \& Engineering Chemistry Research, 53, 13598-13609. http://dx.doi.org/10.1021/ie5012195

[35] Granitza, D., Beyermann, M., Wenschuh, H., Haber, H., Carpino, L.A., Truran, G.A. and Bienert, M. (1995) Efficient Acylation of Hydroxy Functions by Means of Fmoc Amino Acid Fluorides. Journal of the Chemical Society, Chemical Communications, No. 21, 22232224. http://dx.doi.org/10.1039/c39950002223

[36] Perrin, D.D. (1965) Dissociation Constants of Organic Bases in Aqueous Solution. Butterworths, London (Supplement, 1972).

[37] Schwolow, S., Braun, F., Rädle, M., Kockmann, N. and Röder, T. (2015) Fast and Efficient Acquisition of Kinetic Data in Microreactors Using In-Line Raman Analysis. Organic Process Research \& Development, 19, 1286-1292. http://dx.doi.org/10.1021/acs.oprd.5b00184

[38] Colin, B., Lavastre, O., Fouquay, S., Michaud, G., Simon, F., Laferte, O. and Brusson, J.M. (2016) Development of New High-Throughput Screening Method to Compare and to Detect Efficient Catalysts for Adhesive Materials. International Journal of Adhesion and Adhesives, 68, 47-53. http://dx.doi.org/10.1016/j.ijadhadh.2016.02.002 
Submit or recommend next manuscript to SCIRP and we will provide best service for you:

Accepting pre-submission inquiries through Email, Facebook, LinkedIn, Twitter, etc. A wide selection of journals (inclusive of 9 subjects, more than 200 journals)

Providing 24-hour high-quality service

User-friendly online submission system

Fair and swift peer-review system

Efficient typesetting and proofreading procedure

Display of the result of downloads and visits, as well as the number of cited articles

Maximum dissemination of your research work

Submit your manuscript at: http://papersubmission.scirp.org/

Or contact gsc@scirp.org 